\title{
Percursos simbólicos de objetos culturais: coleta, exposição e a metáfora do balcão
}

Symbolic courses of cultural objects: collecting, exhibition and the counter metaphor

\author{
Marcio D'Olne Campos', Luiz Carlos Borges"II \\ 'Universidade Federal do Estado do Rio de Janeiro. Rio de Janeiro, Rio de Janeiro, Brasil \\ "Museu de Astronomia e Ciências Afins. Rio de Janeiro, Rio de Janeiro, Brasil
}

\begin{abstract}
Resumo: Com base em conceitos relacionados ao consumo, à cadeia produtiva (contexto de produção/produto, circulação, consumo) e à discursividade, são analisados aspectos do percurso simbólico de um objeto, desde seu contexto de produção, passando pela musealização, até sua apropriação por um consumidor. Neste percurso, tratamos de noções como valor de uso/valor de troca, que se referem aos diferentes investimentos simbólicos feitos em objetos filiados a diversas redes discursivas. São enfocados diferentes referenciais culturais presentes no manejo do patrimônio, especialmente no que concerne à produção e apresentação museográfica do objeto dirigida ao consumidor, entendendo que, nessa forma de produção e circulação cultural, atuam processos discursivos de ressignificação. Assim, importam as relações que se estabelecem entre um objeto cultural, o produtor, o mediador e o consumidor; bem como o modo pelo qual o objeto sofre interferências ao ser ressignificado. Adota-se o pressuposto segundo o qual as referências culturais do objeto musealizado são discursivamente afetadas ao longo da cadeia que vai do contexto cultural de sua produção ao consumidor. Para fins de análise, é enfocada, principalmente, a exposição "A ciência dos Mebêngôkre: alternativas contra a destruição", versão de 1989, particularmente no que se refere à tradução do sistema de conhecimento Kayapó para uma linguagem acadêmica.
\end{abstract}

Palavras-chave: Cultura. Consumo. Discurso. Exposição. Kayapó. Museu.

\begin{abstract}
Based on concepts related to consumption, productive chain (production context, product, circulation, consumption), and discursivity, we propose to analyze various aspects of the symbolic path an object goes through since its context of production, its musealization until its appropriation by a consumer. In this passage, we deal with some notions such as value of use/value of exchange which refer to different symbolic investments made on objects affiliated to various discursive networks. We focus on different cultural frames present in the management of heritage, with especial regard to the museographic production and presentation of the object towards a consumer, taking into account that, in this kind of cultural production and circulation, several discursive processes of re-signification take place. Thus, what matter are the relations established among a cultural object, the producer, the mediator and the consumer; as well as how the object suffers some discursive modalization when it's re-signified. We assume that musealized object's cultural references are modified throughout the chain that runs from its cultural context of production until the consumer. For the purposes of this analysis, we primarily focus the exhibition "The Mebêngôkre's science: alternatives to destruction", version of 1989, particularly concerning the translation of the Kayapó knowledge system into academic language.
\end{abstract}

Keywords: Culture. Consumption. Discourse. Exhibition. Kayapó. Museum.

CAMPOS, Marcio D'Olne; BORGES, Luiz Carlos. Percursos simbólicos de objetos culturais: coleta, exposição e a metáfora do balcão Boletim do Museu Paraense Emílio Goeldi. Ciências Humanas, v. 7, n. 1, p. 00-00, jan.-abr. 2012.

Autor para correspondência: Luiz Carlos Borges. Museu de Astronomia e Ciências Afins. Rua General Bruce, 586. Rio de Janeiro, RJ, Brasil. CEP 20921-030 (lcborges@mast.br).

Recebido em 28/04/2011

Aprovado em 26/02/2012

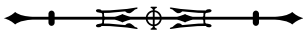




\section{O ESTAR AQUI E O ESTAR LÁ NO BALCÃO}

A visita a uma exposição proporciona, além da experiência sensorial e cognitiva, fazer um percurso modelado por uma elaborada narrativa cujo suporte é seu complexo expográfico1. Eventualmente, os visitantes de uma exposição poderão se perguntar acerca dos diversos deslocamentos por que passa, por exemplo, um objeto etnográfico, desde a sua origem ou procedência (seu local de produção) até o momento em que é posto em exibição. Em termos amplos, práticas e objetos são desenvolvidos nas mais diversas culturas, pesquisadores vão ao campo e aí coletam informações e objetos; findo o período de campo, voltam com suas coleções ao meio acadêmico ${ }^{2}$. A partir daí, o material coletado pode ser canalizado para vários destinos. Algumas vezes - por meio dos pesquisadores, ou não -, transforma-se em mercadoria que circula por um mercado especializado; por outras, é incorporado ao acervo de universidades ou de museus, onde ficarão à disposição de etnólogos, museólogos ou outros especialistas para ser estudado, preservado e exposto ao público. Neste caso, passa à categoria de bens inalienáveis (Gonçalves, 2007a), resguardadas as possibilidades de reivindicação de posse (Borges e Botelho, 2010; Curtis, 2006). No que tange ao direito de propriedade, se os museus consideram os objetos do seu acervo como bens inalienáveis, há uma prevalência do conceito de posse; caso não, então caberia aos museus não a posse, mas a custódia desses bens, como fiéis depositários (Curtis, 2006).

Pensando o transcurso de objetos culturais e as diversas etapas de negociação por que passam, chegamos à metáfora do 'balcão'. Este, no caso de uma loja, é um móvel interposto entre vendedor e consumidor, e sobre o qual transcorre uma negociação. De um ponto de vista mais abstrato, o balcão pode ser pensado como o lugar simbólico de intermediação dentro de um espaço social. Como exemplo, numa das etapas do percurso transcultural de um objeto, este balcão poderia se encontrar interposto entre a equipe de um museu ('revendedores') e os visitantes ('fregueses' da exposição). Em outra etapa, a do trabalho de campo na aldeia, um balcão se interpõe entre os nativos de um grupo étnico e o pesquisador lá presente. Vemos que este recurso teórico pode ser aplicado a diversas situações de negociação, quando intermediadas.

É sob esse ponto de vista que pretendemos promover nossa discussão acerca dos processos de ajuste de referenciais culturais, ou tradução, que ocorrem no percurso transcultural por que passa um objeto etnográfico, pensando a exposição enquanto um tipo de balcão.

Tomaremos uma exposição sobre a ciência dos Kayapó como exemplo de balcão, uma vez que ela faz a intermediação entre o mundo-de-lá (o dos Kayapó) e o mundo-de-cá (o dos visitantes). Importa-nos, sobretudo, pôr em evidência alguns elementos constituintes não apenas do fazer no campo (aparato teórico, relação de estranhamento/familiaridade, tradução do sistema de lá o do objeto sob observação -, para o sistema daqui - o do pesquisador). Ao pensarmos a exposição elaborada a partir do material coletado, catalogado e analisado pelos especialistas, entendida como o fim de um ciclo, importanos enfocar, sob o mesmo ponto de vista, o fazer no museu. Existem, em ambos os casos, modos comuns do saberfazer acadêmico face a objetos, ou segmentos culturais que, de acordo com a terminologia acadêmica, são chamados de etnográficos ${ }^{3}$. Assim, acompanhando o percurso simbólico desses objetos, desde o seu local de produção até a sua musealização, visamos apontar como diferentes

1 Toda exposição se sustenta em um tripé formado por a) apelo sensório-cognitivo, b) comunicação, c) informação. É em torno desse tripé que se constrói o projeto museográfico. Para uma discussão mais ampla sobre a exposição e o papel discursivo do museu, como sujeito ordenador de sentidos, ver, por exemplo, Serrat Antolí e Font Guiteras (2011) e Borges (2011).

2 Tangíveis ou intangíveis, esses dados e objetos, porque têm valor, podem ser considerados patrimônios. Neste caso, pode-se falar de uma dupla relação patrimonial: é patrimônio da (e pela) cultura produtora e é patrimônio da (e pela) cultura receptora.

3 Para uma discussão sobre a relação entre objetos, museus e exposições etnográficas, ver, por exemplo, Regina Abreu (2008) e Goldstein (2008).

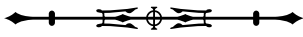


processos de simbolização e categorização interagem com os objetos, deslocando-os e territorializando-os em diferentes espaços simbólicos e, em consequência, fazendo-os produzir diferentes efeitos de sentido.

O sentido, enquanto efeito simbólico-imaginário que se produz entre locutores, é constitutivamente dialógico e intrinsecamente imbricado na historicidade ${ }^{4}$. Como tal, conquanto exista em itinerância, ou em constante circulação, não é errático nem aleatório, uma vez que se desloca de acordo com as condições sócio-históricas. Ou seja, em sua circulação, o sentido, ao percorrer diferentes espaços simbólicos, produz séries de paráfrases, podendo mesmo ressignificar-se. É a partir do campo discursivo do sentido que podemos entender que os objetos culturais também se encontram em deriva simbólica, produzindo diferentes efeitos de sentido, de acordo com os diversos ambientes culturais em que se territorializam.

Em suma, nossa proposta de leitura se fundamenta no pressuposto de que as relações sociais e as interculturais são mediadas por um balcão, entendido como um espaço simbólico em torno do qual transcorrem inúmeras interações sociais. E que o mesmo se aplica aos objetos culturais em trânsito e as exposições.

\section{OS LADOS DO BALCÃO}

O aparato teórico em que se fundamenta a nossa proposta combina noções que envolvem o campo de produção, circulação e consumo (mercado) de bens simbólicos, tangíveis e intangíveis (Bourdieu, 2003, 2009; Gonçalves, 2007a, 2007b); pressupostos conceituais tais como ajuste de referenciais culturais ou tradução, posição relativa, em termos de locus cultural, de especialistas que lidam com culturas e objetos culturais do outro; as complexas relações entre sujeitos, produtos e consumo (Douglas e Isherwood, 2004; Belk et al., 1989), as quais são mediadas por um 'balcão'; além dos conceitos de discurso e circulação de sentidos (Orlandi, 1998). Com base nesse aparato, propomo-nos a fazer uma leitura da exposição "A ciência dos Mebêngôkre: alternativas contra a destruição", realizada pelo Museu Paraense Emílio Goeldi (MPEG) em 1987. Levaremos em conta, ainda, a versão dessa mostra, intitulada "Ciência Kayapó: alternativas contra a destruição", montada no Paço Imperial, no Rio de Janeiro, em 1992, por ocasião da Conferência das Nações Unidas sobre o Meio Ambiente e o Desenvolvimento, mais conhecida como ECO-92. Escolhemos essa exposição por ter sido a primeira sobre essa etnia, por dispormos de dados relativos à sua elaboração e montagem e, relativamente à sua segunda versão, ter sido montada no contexto nacional e internacional da ECO-92.

É pensando em termos de circulação de bens e de sentidos que proporemos, a seguir, um esquema para acompanhar o percurso pelo qual passa um bem patrimonial, desde seu produtor original até ser observado ou desfrutado por um consumidor ${ }^{5}$, em geral, distanciado (social, cultural e geograficamente) do modo/meio de produção desse bem que, mediado por um museu, vem a ser consumido. Assim, dado o modelo de leitura aqui proposto, essas relações (entre produto - produção intermediação - consumo), as quais são marcadas por uma dinâmica tanto espaço-temporal quanto cultural, inserem-se em um sistema de significação que remonta a uma visão/representação do mundo, a qual, por sua vez, deriva de uma prática observacional topo-etno-cêntrica (Campos, 2005; Borges, 1999).

Devemos observar que a cadeia produtiva (concomitantemente econômica e simbólica), que integra produção, produto, intermediário, consumo e consumidor, encontra-se submetida e regulamentada por leis gerais de produção encontradas em qualquer comunidade social e culturalmente constituída; e, de igual modo, devemos ter

\footnotetext{
4 Dá-se, aqui, a distinção básica entre sentido e significado. O sentido não está contido no campo semântico, pois se refere à inscrição da língua em um específico recorte histórico-social. Falar de sentido não é se referir ao conteúdo, mas a uma determinada posição e situação dos interlocutores e de suas práticas de linguagem na sociedade.

5 Para considerações sobre o estatuto e o comportamento do consumidor, ver, por exemplo, Bauman (1998) e Belk et al. (1989).
}

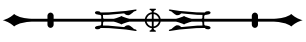


em conta que o consumo, sendo o fim último da produção/ produto, não se desvincula dessa regra geral, conquanto possa exercer forte influência sobre a produção (ritmo de produção, tipologia e qualidade desse produto) e, em certas situações, até mesmo fazer-se destacar (sacralizar, fetichizar) como a culminância da cadeia de produção, especialmente quando se trata de bens simbólicos ${ }^{6}$.

Observemos também que todo produto, ou bem simbólico, encontra-se investido de valor de uso e de valor de troca. Consideramos aqui o valor de uso como o valor primário e diretamente relacionado à produção; ao passo que o valor de troca, enquanto valor agregado - em que se dá um investimento de valor supra-simbólico direta e indiretamente relacionado à importância de qualquer bem numa relação de troca -, é o valor de que se investe qualquer produto numa relação com o outro, aquele que, na configuração espacial e metafórica que estamos utilizando, se encontra do outro lado do balcão.

Vale ressaltar que o valor (seja intrínseco, seja atribuído) de um bem difere substancialmente caso este bem esteja em seu contexto original de produção, ou em outro contexto cultural para o qual foi deslocado (contexto de recepção). Assim, enquanto se encontra em seu contexto original, um objeto está basicamente investido de valor de uso e, só secundariamente, é-lhe agregado um valor de troca. Estando fora do seu contexto, entretanto, essa relação tende a se inverter, qual seja, aumenta seu valor de troca e diminui seu valor de uso. Ao lado desses dois valores, devemos considerar também outros valores de que podem estar investidos objetos culturais (ou bens patrimoniais). Walter Benjamin mostra que, em determinados contextos, os objetos podem ser investidos de valor de culto e de valor de exposição (Benjamin, 1994). Essa assertiva benjaminiana é secundada por Belk et al. (1989), ao tratarem das formas de sacralização das mercadorias ${ }^{7}$.
Recordemos que tanto os objetos quanto os valores de que estão investidos integram o campo de produção (e de consumo) de bens simbólicos, e que este, como qualquer outro campo, se constitui como uma estrutura social de relações objetivas (Bourdieu, 2009). Assim, a linha de produção que vai do trabalho de campo à exposição, enquanto segmento do campo da produção cultural, faz parte da estrutura das formas ideológicas de que fala Marx (2004). Por outro lado, devemos considerar que, de maneira bastante particular, o campo de produção cultural, para além de suas relações objetivas, investe-se, igualmente, daquilo que Bourdieu chama de "lógica propriamente mágica da produção do produtor e do produto como feitiços" (Bourdieu, 2009, p. 67). Isto significa que, no tocante aos processos de produção, as relações subjetivas também importam, considerando-se que as determinações de caráter subjetivo desempenham um papel relevante no quesito criatividade.

Trata-se de um aspecto importante, especialmente quando consideramos uma exposição. Muitas vezes, é possível detectar um teor (implícito ou explícito), se não mágico, de sacralização e de fetichização de que os objetos expostos ficam investidos, particularmente quando o tema da exposição é artístico ou etnográfico (Benjamin, 1994; Bourdieu, 2009; Belk et al., 1989).

Desse modo, e pensando o balcão como representação do ato e do ator da intermediação, propomos o seguinte esquema:

Produção
[Produtor/Produto]
$\downarrow$
Balcão
[Consumidor/Mediador]
$\downarrow$
Consumidor final

6 De acordo com Marx (1978), o consumo, no qual o objeto consumido se subjetiva ao se converter em objeto e serviço da necessidade individual, satisfazendo-a no desfrute, cria a necessidade de novas produções.

7 Embora em momentos e situações diferentes, tanto o enfoque de Benjamin quanto o de Belk et al. mostram similaridade com o processo de fetichização da mercadoria que, de acordo com Marx, decorre da ocultação "(...) do caráter social próprio do trabalho que produz mercadorias" (Marx, 1971, p. 81).

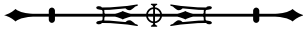


Antes de tratar especificamente da itinerância de objetos culturais, devemos reafirmar que esse esquema geral da produção/consumo ocorre em qualquer sociedade. Quanto mais complexa for uma sociedade, mais diversificadas serão as suas relações sociais, portanto, mais intermediações e mais desdobramentos serão encontrados, incluindo a relação que se dá entre duas ou mais sociedades. Assim, no interior de uma sociedade do tipo indígena, a relação produto/consumo pode dar-se de modo direto, uma vez que, em geral, concerne a uma relação entre atores assemelhados ou simétricos (entre indivíduos da mesma aldeia ou, extensivamente, do mesmo grupo étnico); ou entre indivíduos culturalmente diferenciados (entre indivíduos de grupos étnicos diferentes); ou, ainda, entre um indivíduo indígena e um que pertença à sociedade envolvente, portanto, dessemelhantes e até mesmo assimétricos $^{8}$. Neste último caso, a presença de intermediários pode ser exigida, especialmente quando se trata da relação entre atores social, econômica, política e culturalmente dissimétricos. É o que ocorre, por exemplo, em rituais nos quais é invocada a presença de entidades sobrenaturais ou divinas. Neste caso, o produto (a entidade) é levado ao consumidor final (em alguns casos, exclusivo), por meio de um processo simbólico (o ritual) e sob a supervisão de um especialista (pajé, xamã, líder espiritual).

Nosso interesse, todavia, concerne ao patrimônio etnográfico e à relação que se estabelece entre um produto primário, ou original, o intermediador - que atua como recontextualizador/repassador do produto ou objeto e que também se assume como consumidor - e um consumidor final. Em nosso caso, chamamos de consumidor final o indivíduo que visita uma mostra ou exposição, a respeito de quem não é possível, a priori, determinar a condição social, econômica, geográfica ou cultural, dada a sua diversidade.
Tem-se, em geral, mas não necessariamente, que se trata de indivíduos culturalmente distantes do produtor original.

\section{O BALCÃO: ENTRE O AQUI E O LÁ DA CULTURA}

Temos, então, a partir do balcão, aquele que lida tanto com o produtor original como com o consumidor final, a quem chamaremos de Ego. Hipoteticamente, é factível supormos haver casos em que seja possível observar mais de um balcão, por exemplo, o que se põe entre o produtor original (um artista plástico) e um marchand (ou dono de galeria), e entre este último e uma instituição museal, assim como entre a obra exposta e o visitante. Nesta configuração, Ego desempenha simultaneamente o papel de produtor/recontextualizador e de consumidor intermediário. O balcão é sempre o ponto de partida, ou de referência, para que possamos observar e compreender o percurso - e as relações sociais e simbólicas - do produto desde sua origem até o consumidor final.

Levando em conta que a relação entre produtor intermediário e consumidor final é mais complexa, devido precisamente à indeterminação deste último, e considerando ainda os dados disponíveis, relativos à produção da exposição Kayapó, restringiremos nosso enfoque à relação entre produtor original e produtor intermediário/recontextualizador. Com base nisso, devemos pensar no deslocamento de objetos e dados etnográficos (cultura material ou imaterial) por meio das etapas mencionadas acima. Isso nos leva a propor um esquema geral do tipo: objeto (campo) > pesquisador (academia: publicações, seminários) > museólogo (museu, coleção) > balcão (exposição) > público.

Em cada uma dessas etapas, podem coexistir diferentes pontos de vista ou referenciais culturais. Por exemplo, entre os nativos numa aldeia, podem estar presentes antropólogos, museólogos, indigenistas ou

\footnotetext{
8 Remetemos a Gordon (2006) para uma discussão mais ampla acerca do sistema de produção, circulação e consumo de bens entre os Kayapó Xikrin.
}

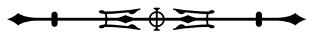


missionários. No caso da exposição Kayapó, havia uma família Kayapó interagindo com a equipe de montagem da exposição e muitos Kayapó visitaram a exposição. Situações como essa configuram diferentes referenciais culturais, interagindo em variados graus de tensão e de ajuste.

Se os referenciais são diferentes - inclusive numa mesma sociedade -, é preciso que eles se ajustem e permitam tradução, em benefício da comunicação. Esse tipo de problema é abordado por Clifford Geertz (1999, p. 226), ao discutir que:

(...) o fato de que o pensamento é espetacularmente múltiplo como um produto e maravilhosamente singular como processo, tornou-se um paradoxo vivo e cada vez mais poderoso nas ciências sociais. (...) A natureza desse paradoxo foi sendo cada vez mais associada aos enigmas da tradução, ou seja, à forma pela qual um determinado significado em um sistema de expressão é expresso em outro sistema - hermenêutica cultural, não mecânica conceptiva.

Com relação às afirmaç̧ões identitárias, isto é, às distâncias culturalmente relativas entre eu (ou nós) e um outro (ou eles), e da forma como essas distâncias são percebidas, representadas e manipuladas pelos povos, Geertz oferece uma interpretação relevante, especialmente quando, a partir desse gradiente de distanciamento, temos de lidar com a tradução:

Agora somos todos nativos, e os que não estejam por perto são exóticos. Qualquer outra pessoa que não seja imediatamente um de nós é um exótico. Aquilo que antes parecia uma questão de descobrir se selvagens eram capazes de distinguir fatos de fantasias, hoje parece ser uma questão de descobrir como é que outros, além-mar ou do outro lado do corredor, organizam seu universo de significados (Geertz, 1999, p. 226).

O fato das diferenças estarem mais perto de nós do que possamos imaginar, leva-nos a refletir com mais cuidado sobre o processo que conduz a nós, acadêmicos, desde a aldeia indígena, 'entre nativos', passando pela preparação técnica dos objetos e da elaboração da exposição até o contato com o público (consumidor pleno ou final de uma exposição).
Um etnógrafo, ou qualquer outra pessoa que se defronte com diferenças no contato social e esteja interessado em dialogar com o outro, acaba, mesmo que instintivamente, adaptando seus referenciais em benefício da melhor compreensão no diálogo. Se o interesse for mútuo, o outro também fará esse esforço. Isso significa que pode estar ocorrendo um ajuste mútuo de referenciais, ou intertradução. A finalidade desse esforço é aumentar o mais possível o nível de inteligibilidade entre os locutores, em uma cena discursiva, em que cada um procura encontrar, em seu próprio sistema de referenciais culturais, um lugar de significado para as referências culturais do outro (Campos, 2000, 2002, 2009).

Como já mencionado, durante o período de elaboração da exposição, o Museu Paraense Emílio Goeldi teve a consultoria da família de Kwyra Ká Kayapó. Este era um importante xamã e um especialista em abelhas. Portanto, no contexto do mundo Kayapó, exercia duplamente a ciência.

Os pesquisadores que participavam do Projeto Kayapó estiveram 'lá', na aldeia Gorotire (Pará), e trouxeram os dados ali coletados para trabalhá-los 'aqui', no meio acadêmico do MPEG. O estar aqui e o estar lá se referem às etapas do trabalho etnográfico do antropólogo, segundo Clifford Geertz (1989), ao falar da situação de 'estar lá' no campo entre os outros e a de voltar à academia, no 'estar aqui', interagindo e discutindo com os seus pares, para, a seguir, dedicar-se ao 'escrever aqui' do texto etnográfico. É claro que o pesquisador, mesmo estando fisicamente no 'estar lá' do campo, ao se deparar com algum fato, evento ou fenômeno que lhe seja estranho, necessita recorrer ao seu referencial próprio de saberes e teorias do 'estar aqui' da academia, para poder conduzir sua análise sobre os dados observados e coletados no 'lá' do campo. Podemos pensar que essa situação se inverte no caso de Kwyra Ká, para quem o MPEG é o seu 'estar lá' no campo, percebendo outra cultura, antes de voltar ao 'estar aqui' da aldeia Gorotire, entre seus pares.

Consideremos, agora, em relação ao esquema do balcão, alguns aspectos da relação entre estar aqui e estar lá, presentes na discussão acima. No estágio inicial da

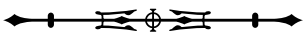


produção, Kwyra Ká poderia estar na aldeia, ou seja, de acordo com o seu referencial cultural, no seu 'estar aqui', equivalente para nós, pesquisadores, ao 'estar lá', na aldeia, contexto cultural do outro. Quando ele se encontrava como consultor Kayapó, 'lá' no MPEG, a situação se inverteu, pois nesse lugar instaurou-se um balcão anterior (no tempo e no espaço) à abertura da exposição. Este é o 'aqui' dos pesquisadores (consumidor/reelaborador), que, em colaboração com a equipe de museologia (intermediário/realizador), prepara a mostra.

\section{A EXPOSIÇÃO E AS EQUIVALÊNCIAS CULTURAIS: UM CASO DE TRADUÇÃO/MEDIAÇÃO}

Nos anos 1980, sob a coordenação de Darrell A. Posey, um grupo interdisciplinar de cerca de vinte cientistas realizava pesquisas de caráter etnoecológico sobre os conhecimentos da etnia Kayapó junto à aldeia Gorotire, localizada a sudeste do estado do Pará, às margens do rio Fresco, afluente do rio Xingu. Os resultados parciais dessas pesquisas forneceram subsídios para a elaboração de duas exposições relativas aos saberes e às práticas, ou melhor, à ciência dos Kayapó.

As duas exposições foram montadas, respectivamente, em Belém, no MPEG, em 1987, e no Rio de Janeiro, no Paço Imperial. Esta última foi inaugurada durante a Conferência das Nações Unidas sobre o Meio Ambiente e o Desenvolvimento, mais conhecida como ECO-92, realizada no Rio de Janeiro entre os dias 3 e 14 de junho de 1992. Seus títulos respectivos foram "A Ciência dos Mebêngôkre: alternativas contra a destruição" e "Ciência Kayapó: alternativas contra a destruição", os quais correspondem aos títulos dos catálogos que foram editados pelo MPEG (Hamú, 1987; Oliveira e Hamú, 1992).
Os Kayapó se distribuem por uma extensão importante do Brasil central, com aldeias no Parque Indígena do Xingu, ao norte do estado de Mato Grosso e ao sul do estado do Pará. Com quase 20 aldeias, a população total, em 2010, era de 8.638 habitantes, de acordo com a Fundação Nacional de Saúde (FUNASA) 9 . A aldeia Gorotire, na qual foi desenvolvida a pesquisa do Projeto Kayapó, se localiza no Pará, à margem direita do rio Fresco, afluente do rio Xingu. Falam o Kayapó Gorotire, língua que integra o grupo linguístico Kayapó, um membro da família Jê, por sua vez, uma das subdivisões do Tronco Macro-jêêt.

Cabe notar que o termo 'kayapó' (do tupi kaya 'macaco' e pó - 'semelhante a') é a denominação pela qual esse grupo é genericamente conhecido pelos outros grupos indígenas e pela sociedade envolvente. $\bigcirc$ termo significa cabeça de macaco e se refere, possivelmente, ao modo como os Kayapó cortam os cabelos, deixando uma área raspada na forma de um triângulo a partir da testa ${ }^{11}$ (Turner, 1998; Verswijver, 2002). Essa denominação começou a ser usada a partir da segunda metade do século XVII, para designar índios então conhecidos por bilreiros (Kayapó meridionais, no sul de Goiás), depois foi estendida para abarcar os Kayapó setentrionais (situados entre o Tocantins e o Araguaia). De fato, eles preferem a autodenominação de Mebengôkrê, que significa povo ou homem do olho d'água, expressão que remete ao mito de origem desse grupo (Lukesch, 1976; Arnaud, 1989; Machado, 1992a; Turner, 1998; Povos..., s.d. ${ }^{12}$ ).

Vamos nos deter mais sobre a primeira exposição que, em sua elaboração, envolveu experiências interessantes de contatos preparatórios com os Kayapó, tanto na aldeia Gorotire, quanto no próprio Museu Paraense Emílio Goeldi.

9 Segundo informação colhida no site do Instituto Socioambiental (ISA, s.d.).

10 O grupo linguístico Kayapó se compõe das seguintes línguas: Gorotire, Kararaô, Kokraimôro, Kubenkrangnotí, Kubenkrankêng, Menkrangnotí, Tapayuna, Txukahamãe (Mentuktíre) e Xikrín (Rodrigues, 1986). Para uma síntese da história dos grupos Kayapó, consultar Arnaud (1989) e Turner (1998); para uma lista de fontes sobre os Kayapó, ver Verswijver (2002) e Povos... (s.d.).

11 Outra explicação para a associação entre os indivíduos dessa etnia e os macacos deriva do fato de, na Dança dos Macacos (kukoire-to, em língua kayapó), os homens portarem máscara de macaco enquanto dançam e cantam (Verswijver, 2002).

12 Com pequenas diferenças e sem menção de autoria, esse texto é o mesmo publicado em 2002, no site do Instituto Socioambiental (ISA), por Gustaaf Verswijver.

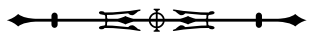


A concepção museológica esteve a cargo de Denise Hamú Marcos de La Penha e a cientííca, a cargo de Darrell A. Posey, coordenador do Projeto Kayapó, que abrigava cerca de vinte pesquisadores dedicados a ramos específicos da etnociência. Darrell Posey e Denise Hamú promoveram reuniões na aldeia Gorotire, nas quais trocaram ideias e discutiram com os Kayapó a temática, a dinâmica e os preparativos da exposição. Estavam presentes nessas reuniões os caciques Kanhonk e Totoí, assim como os pajés Beptopup e Kwyraká, além de outros indivíduos da comunidade. Em particular, Kwyra-ká Kayapó e família integraram-se ao Departamento de Museologia do MPEG e atuaram, por dois meses, como consultores permanentes da mostra.

Os textos da exposição e do catálogo foram elaborados por Darrell Posey (Antropologia e Etnobiologia), Elaine Elisabetsky (Etnofarmacologia), Anthony Anderson (Etnobotânica e Etnoecologia), Marcio D'Olne Campos (Etnoastronomia), Adélia Rodrigues de Oliveira (Antropologia) e Guilherme De La Penha. A seguir, serão descritos, de forma sucinta, os setores e elementos que compunham a primeira exposição, com destaque para os aspectos cosmológicos e as relações entre céu e terra que levaram à elaboração de um círculo de tempo kayapó.

A exposição apresentava-se numa sequência de módulos temáticos, segundo a estrutura seguinte:

1. Introdução

2. Aspectos cosmológicos, etnoastronômicos e de conhecimento sobre as relações entre céu e terra

Mundo cosmológico

Calendário ecológico

\section{Aspectos históricos}

Sala de vídeo

Aldeia antiga

Mudança cultural

Devastação da Amazônia

4. Aspectos ambientais: científicos, etnobiológicos e etnoecológicos

A Ciência dos Mebêngôkre: alternativas contra a destruição
A sala de Introdução continha textos com informações básicas sobre a etnia Kayapó e um diorama representando um contexto cotidiano da aldeia. Em seguida, uma vitrine apresentava uma importante peça de ornamento, o Mekutom, capacete-cocar que simboliza muitos aspectos do mundo cosmológico kayapó, muitos destes mostrados na sala escura, que, na estrutura narrativa da exposição, vinha depois da sala de Introdução. Seguindo-se a esta, a próxima sala apresentava os marcadores de tempo da natureza e das atividades sociais por meio de um calendário ecológico, ao qual se associam eventos cíclicos sazonais observáveis ao longo do ano em Gorotire (Campos, 2006).

Uma maquete da aldeia antiga (pykatôti) - a primeira aldeia que reunia a maior parte dos Kayapó no início do século $X X$ - remetia aos aspectos históricos do mundo kayapó. Depois das duas primeiras décadas, ocorreram muitas 'doenças dos brancos', assim como tensões internas, que provocaram a separação dos Kayapó em muitas direções e aldeias menores. Além disso, uma maior intensidade do processo de mudança cultural se instaurou a partir do início dos anos 1980, devido, principalmente, ao crescimento da exploração do ouro e de madeira em Gorotire. Surge uma estrada e, com isso, a necessidade de gerar mais recursos para a obtenção dos produtos industrializados que passaram a ser introduzidos, juntamente com contatos com os mais diversos setores da sociedade envolvente. Acrescentese a isso diversos choques culturais que se seguiram, diante da necessidade desse povo defender suas terras contra invasores (garimpeiros, fazendeiros, posseiros e especuladores). Tudo isso se somava, contribuindo para um acelerado processo de destruição da reserva Gorotire. Note-se que este é um exemplo significativo do que se passava (e se passa ainda) em várias outras regiões, onde os conhecimentos indígenas e suas práticas de manejo ambiental se encontram ameaçados, em grande parte, como consequência da devastação da Amazônia.

Os Kayapó classificam seus recursos naturais em diversos ecossistemas. Em relação a cada um deles, 
reconhecem uma associação específica entre plantas e animais, sabendo quais plantas interessam a cada animal. Além disso, eles conhecem bem a variedade de solos ao qual se adaptam espécies diversas de plantas. Dessa forma, cada ecossistema por eles classificado forma uma unidade coesa de interações entre plantas, animais, solo e o próprio homem (Posey, 1986; Machado, 1992b, 1992c; Borges e Gondim, 2003). No interior desses ecossistemas, encontramos outras facetas do consistente e sistemático conhecimento kayapó acerca da natureza, expresso na fala e nas ações de vários especialistas locais, muitos deles já investidos de capacidades xamânicas, os denominados wajanga. O último setor da exposição mostrava "A Ciência dos Mebêngôkre: alternativas contra a destruição".

Os saberes nativos estavam apresentados e representados em conformidade com a metodologia e a expertise com que foram analisadas, pelos especialistas que integravam o Projeto Kayapó, as diversas áreas e os ramos da ciência kayapó. Dessa forma, os conhecimentos nativos foram traduzidos, remodelados e apresentados sob denominações diversas, tais como etnobiologia, etnoecologia, etnofarmacologia, etnoapicultura e outras nas quais se subentende o termo genérico etno- $X$, onde $X$ é alguma área de saber presente na sociedade abrangente, ou na ciência instituída, e o prefixo 'etno-' refere-se à observação e análise etnográfica empreendida sobre esses saberes locais (Campos, 2002; Borges, 1999; Borges e Gondim, 2003).

Vale lembrar que essa última parte da exposição se apresentava numa trilha inspirada nas trilhas kayapó, as quais, em seus quilômetros de percurso, foram projetadas para que sempre pudessem ser encontrados recursos para o aprovisionamento cotidiano do grupo, sobretudo nos apêtê ('ilhas de fertilidade'), pontos de descanso ou dormida. $\mathrm{Na}$ exposição, essa era denominada a 'trilha do conhecimento'.

\section{O MEKUTOM}

Consideremos de forma mais detalhada as duas primeiras salas. Antes da sala escura do Mundo Cosmológico, expunha-se, numa vitrine, o Mekutom (Figura 1), que, nos catálogos das duas versões da exposição, vem descrito da seguinte forma:
a) capacete de betume, pintado em vermelho e branco. Enfeite de tala prendendo um cocar com armação de taboquinhas cobertas com fios de algodão e penas de arara vermelha e azul e papagaio. Fabricação e uso masculino. Medida: $85 \mathrm{~cm}$ de altura. Coleção particular (Hamú, 1987, p. 42).
b) capacete de betume, com pintura em branco e vermelho. Na parte mais elevada é colocado o adorno emplumado. A faixa vermelha representa o caminho do sol e os braços indicam as orientações norte e sul que simbolizam os locais das roças (Santana e Rodrigues, 1992).

Mekutom é usado pelos homens durante o ciclo ritual composto de várias festas, nas quais os jovens que estão entrando na adolescência recebem seus novos nomes, que coincidem com nomes de seus antepassados (Festas do Bemp). Nessas festas, realizadas entre julho e setembro, durante o início da estação de pesca, são cantadas músicas que os homens aprenderam com os peixes no tempo antigo (amrê bê), quando os homens e os peixes conversavam.

Através desse capacete-cocar, o visitante é introduzido ao Mundo Cosmológico kayapó. $\bigcirc$ cocar representa o sol e também o universo que, segundo os Kayapó, é constituído de várias camadas (mundos), representadas no Mekutom pelos bordados de fios de algodão de diversas cores. De fato, o Mekutom é uma representação plástica da mítica passagem dos Kayapó do mundo-de-cima para o mundo-de-baixo (do céu para a terra) ${ }^{13}$.

\footnotetext{
13 Lukesch (1976) apresenta duas versões ou perspectivas desse mito. A dos que estavam, ou permaneceram, no mundo-de-cima (koikwa, palavra para designar o céu e também o teto da casa) e que, pelo buraco cavado pelo tatu, vislumbraram o mundo-de-baixo (mundo abaixo de nós); e a dos que, vivendo no mundo-de-baixo, contam como outrora seus antepassados chegaram vindos do mundo-decima (mundo acima de nós). Aos demais mundos, abaixo do mundo em que vivem, atualmente, os Kayapó, chamam puká-óndyu ('mais um mundo, ou terra') ou atema puká ('outro mundo, ou terra').
}

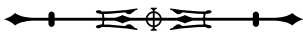




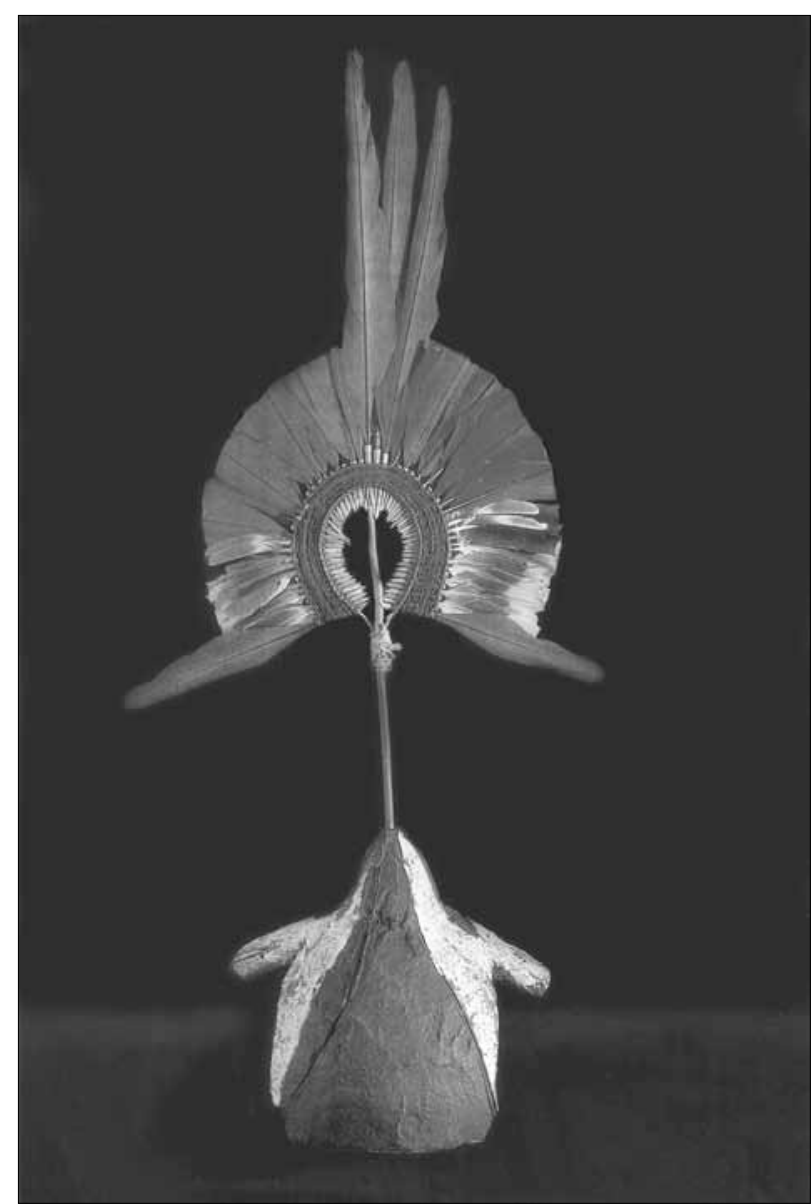

Figura 1. Mekutom. Fonte: Oliveira e Hamú (1992).

Uma das camadas é aquela onde vivem os habitantes de Gorotire e de outras aldeias, como as do Parque Nacional do Xingú 14$^{4}$. O mito da descida dos Kayapó conta que os caçadores desceram, por uma corda, da camada de cima para a camada de baixo, onde vivem hoje os Kayapó de Gorotire. A descida ocorreu a partir do buraco cavado por um enorme tatu, que, de tão profundo, perfurou a crosta que separa as camadas, permitindo, assim, não apenas a visão desse outro mundo, como também a sua travessia. Uma haste de madeira, que sustenta o cocar sobre o capacete, simboliza a corda da descida. Por conseguinte, a camada para onde eles desceram e que hoje habitam é representada pelo capacete de betume (Posey et al., 1987; Campos, 2006).

Passando pelo Mekutom, penetrava-se numa sala escura configurada como uma abóbada celeste. Na cúpula, estava representado o céu do mundo kayapó em tempos remotos, quando ocorreu um eclipse total do sol, relatado pelos mais velhos da aldeia. Ao ver o sol 'escurecer', eles se lembraram do buraco de tatu pelo qual os antigos haviam descido para esse mundo. Por isso, havia no centro da sala um disco negro, com alguma luz difusa nas bordas, representando o eclipse. Dele, partia verticalmente um jato de luz laser representando a corda da descida. Distinguemse, na cúpula, o planeta Vênus (Nhak-pok-ti, considerada como a filha do 'dono das chuvas' e fornecedora dos primeiros tubérculos para a agricultura) e a Via Láctea (moi ngrôt), que os Kayapó percebem como as cinzas resultantes da queima de um grande pé de jatobá. Nessa configuração do céu, a Via Láctea intercepta ('corta') em ângulo reto os caminhos do sol e da lua, representados por duas linhas paralelas traçadas no céu, assim como no chão.

Para maiores informações sobre o Mundo Cosmológico, os visitantes dispunham de fones com narrativas em português, inglês e kayapó. Entrava-se na sala pelo lado do nascente, onde estava desenhada, numa cortina, a grande teia de aranha. Trata-se de um portal que os espíritos $\left(k^{2} r_{0}{ }^{15}\right)$ dos iniciantes a pajé têm que atravessar para visitar um outro mundo de perigos. Entre esses perigos, sobressaía a figura do Ok-ti - ave gigante, ou grande águia, que, nos primórdios da vida na terra-de-baixo, aterrorizava os Kayapó. Os que de lá retornam vitoriosos, reintegram-se ao corpo e se tornam

\footnotetext{
14 Nas demais camadas-mundo vivem outros seres e também outros Kayapó, como aqueles que, segundo o mito de origem, não desceram para a camada-mundo onde vivem os Kayapó de Gorotire. Assim, o céu de uma camada é também o solo da camada superior. Por isso, para os habitantes de Gorotire, os pontos de luz que brilham à noite no céu (estrelas) são as fogueiras dos que vivem na camada superior.

15 Karon: 'alma' ou 'sombra', assim, meõ-karon ou mekaron, 'sombra de homem', 'sombra humana', ou condição existencial de um homem após sua morte, viver como sombra: alma/espírito dos mortos.
}

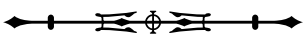


pajés consagrados. Vários espíritos de animais mitológicos estão desenhados nas partes mais baixas da representação do céu. A saída da sala ocorria no lado do poente, onde se encontrava a caverna dos espíritos e o lar dos grandes pajés. Na cortina, aparecia a representação do espírito (karon) de um pajé e de uma onça, cujo espírito também aí habita e que pode se metamorfosear em pajé.

\section{O CÍRCULO DO TEMPO}

$\mathrm{Na}$ interação com o meio em que vivem, os Kayapó permanecem atentos aos sinais de mudanças na paisagem à medida que vão se passando as estações do ano. Essa atenção se concentra também no aparecimento de uma sequência de estrelas observadas ao longo do ano e sempre na direção do nascente ou na direção do alto do céu, antes do sol nascer.

Para esse povo, os fenômenos celestes não são sujeitos a interferências da ação do homem e permanecem os mesmos por mais que os efeitos humanos sobre o meio ambiente terrestre modifiquem a forma e o tempo em que eventos ocorrem. Nesse caso, por exemplo, a construção próxima de uma represa pode alterar o clima, o regime de chuvas, a fauna aquática e o aparecimento de flores e frutos durante o ano. Mas isso não altera o aparecimento sazonal e sequencial das estrelas ao longo do ano. Ou seja, podem-se estabelecer alguns descompassos entre marcadores celestes e terrestres.

Esse conjunto de saberes e técnicas sobre o tempo, que poderíamos chamar de calendário ecossistêmico, tem a vantagem de permitir, através dos fenômenos celestes precisamente repetidos anualmente, uma forma de controle ambiental das anomalias passíveis de existirem nos marcadores ambientais terrestres do tempo.

A sala que expunha o calendário mostrava desenhos, fotos e exemplares dos marcadores de tempo naturais e sociais sobre as paredes, indicando, no perímetro da sala, o caráter cíclico do aparecimento desses marcadores terrestres que a cada ano ressurgem com alguma regularidade. Sobre a parede e a partir do chão, era indicado, por uma faixa na cor marrom, o nível da água do rio Fresco, que banha a aldeia. Quatro pequenas cúpulas estavam distribuídas ao longo da sala, mostrando a configuração dos marcadores celestes em certas épocas do ano. Os marcadores mais importantes são o 'montinho de cinzas', representando o aglomerado estelar das Plêiades (ngrôt krure) e as 'cinzas do pé de jatobá', representando a Via Láctea, nas posições aproximadas em que ela se configura em relação à linha nascente-poente: paralela, ou cortando o caminho do sol.

Um conjunto de marcadores celestes e terrestres do tempo aparece sintetizado no Círculo do Tempo (Figura 2). No centro, o desenho oval representa os períodos de chuva e seca, assim como os da cheia e vazante do rio. O círculo exterior a essa oval representa, segundo o pajé Beptopup, as luas (meses) contadas sempre a partir do início da fase crescente que sucede imediatamente à lua nova. Dos cinco círculos mais externos da figura, os três primeiros representam atividades próprias do aprovisionamento nas relações homem-natureza (brocar, plantar e pescar, caçar, colher). As atividades de lazer, rituais e cerimoniais estão representados nos dois círculos mais externos e, de algum modo, dividem socialmente o ano em quatro grandes ciclos: Festas do Bemp, da roça, do milho, da mandioca e o ciclo de lazer.

O ano kayapó começa por volta do mês de junho, no 'tempo bonito' (mêx). Nessa época, já se começa a ver o bemp-nhõ-djá, raios crepusculares coloridos que se irradiam a partir do sol, próximo ao poente. As Plêiades aparecem próximas ao horizonte, antes do sol nascer, e o rio ainda mantém o nível mais alto das águas durante cerca de duas luas. $O$ ciclo do lazer permite preparar os artesanatos e ornamentos para as Festas do Bemp e da roça. Éa partir desse ciclo que começa a estação da pesca, cujo prolongamento ocorre por cerca de seis luas até a festa do milho.

Por volta do início do mês de agosto, o rio já está mais baixo (ngô ngra, 'água rasa' ou vazante), crescem as praias e as ilhas, a pesca se intensifica, as roças já foram preparadas e começa o plantio. O macaco guariba

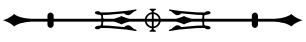




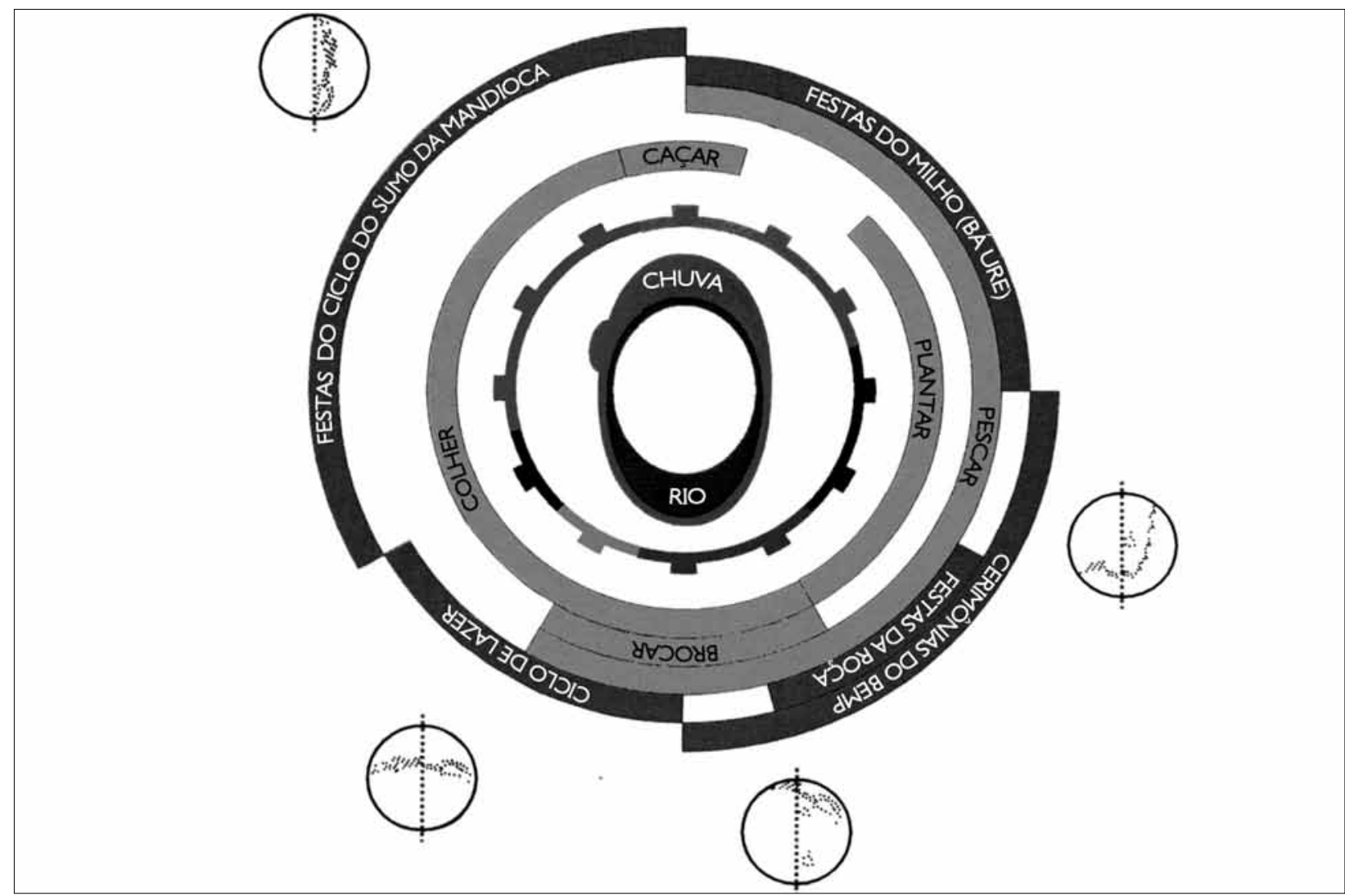

Figura 2. Círculo do Tempo. Fonte: Campos (2006).

(Alouatta belzebul), que esteve engordando antes desse período, começa a emagrecer e a 'cantar'. Aparece a flor do pente de macaco (Amphilophium crucigerum), a banana-brava (Heliconia sp.) e se ouve o canto do gavião real (Harpia harpyja).

No final de setembro, as Plêiades são observadas no alto do céu, antes do amanhecer. Aí termina o ciclo do Bemp, com sua última festa. Isso ocorre durante o plantio e representa um marco de divisão entre o plantio de espécies próprias de 'terra seca' e aquelas de 'terra molhada', pois é o momento de chegar a primeira chuva, ainda fraca, mas que anuncia o período de outras mais intensas. A aldeia é invadida pelas saúvas de asa e surgem, na beira do rio, a flor do sarão, ou murta, e muitas borboletas brancas.

Em novembro, encerra-se a atividade de pesca com a busca do tracajá (Podocnemis uniflilis); com as fortes chuvas, frutos e castanhas caem no chão e atraem os animais, que, por sua vez, atraem os caçadores. Nesse período de caça mais intensa, termina a festa do milho (que se seguiu à do Bemp) e começa a festa da mandioca, que se estende por cerca de cinco luas até o início do tempo bonito do verão. Pouco depois do início da festa da mandioca (fevereiro), a Via Láctea pode ser observada, antes do amanhecer, mais ou menos alinhada com o caminho do sol (leste-oeste). $\bigcirc$ rio começa a ficar mais cheio; é o período da 'água funda' (ngo tum). As colheitas preponderantes são as de milho, melancia, abóbora e banana.

Com o recomeço do ano, em pleno ciclo do lazer, na transição maio-junho, a Via Láctea aparece, ao amanhecer, cruzando (cortando) o caminho do sol. Reinicia-se, então, a preparação de artesanatos e dos ornamentos usados em várias atividades, sobretudo em festas e rituais.

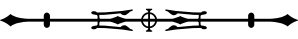




\section{A ITINERÂNCIA DOS OBJETOS E O BALCÃO}

Tanto a sala do calendário como o Círculo do Tempo são construções feitas pelos pesquisadores acadêmicos (no 'estar aqui') do Projeto Kayapó, em decorrência do trabalho de campo etnográfico junto aos especialistas locais (no 'estar lá'), o que significa que são artefatos criados a partir de uma percepção local do tempo, imbricada ao modo de vida e à organização social dos Kayapó de Gorotire, inseridos no seu ambiente natural e social.

As noções de 'estar aqui'/'estar lá', associadas ao modelo do balcão, aplicam-se, por exemplo, ao uso expositivo do Mekutom, o qual foi transposto da aldeia para a coleção do museu, e desta para a exposição. Observemos que, na transposição do Mekutom do seu contexto original (aldeia) para o da exposição, ele sofre um processo de recontextualização e, consequentemente, de ressignificação, ao ser exposto no 'aqui' de uma vitrine, deslocado de sua temporalidade e das condições socioambientais em que era exposto na aldeia ('lá').

Usando o esquema acima proposto, teríamos: o deslocamento do Mekutom da aldeia (contexto de produção), de onde foi recolhido por pesquisadores (consumidor/reelaborador), que, juntamente com a equipe de museologia (intermediário/realizador), propõem - atravessando a etapa do balcão - que a peça seja posta em um cenário para fruição do visitante (consumidor final). Ao se tornar constituinte de um enunciado expositivo, o Mekutom coloca-se para além do 'estar aqui' da academia. Esse deslocamento, mais do que espacial, ou cultural (da cultura da aldeia para a cultura do museu), retira o objeto de sua cadeia discursiva para cenografá-lo em uma formação histórico-ideológica que lhe é totalmente estranha.

No caso do Círculo do Tempo, a situação é mais complexa, uma vez que não se trata mais de um objeto, mas de um constructo, no qual o saber dos Kayapó sobre o tempo é transposto (traduzido) com e para os referenciais culturais do saber acadêmico. Assim, o calendário ecológico configura-se como um 'estar aqui' baseado no que os pesquisadores colheram como informação a partir da interação com os Kayapó (no 'estar lá').

Aqui, aparecem nuances interessantes se pensarmos o material e o imaterial (tangível/intangível) como extremos de uma escala, ainda que descontínua, especialmente em relação a possíveis reivindicações de restituição ou repatriamento. Devemos notar que, na predominância do intangível, é mais difícil para os nativos disporem de embasamento para reivindicar repatriamento. Essa dificuldade aumenta proporcionalmente quanto maior for a distância cultural entre o meio-origem (o da aldeia) e o meio-alvo (Thieberger, 1980) do que foi traduzido (exposição). Observemos, no que tange ao processo de ajuste de referenciais entre participantes de uma cena intercultural, que estes buscam encontrar em seu sistema representações, equivalência e validade cultural para aquilo que foi produzido por uma cultura que lhes é estranha (Thieberger, 1980). Ressalvemos que equivalência e validade não significam identidade, mas tão somente ajuste ou adequação entre sistemas. Assim, uma exposição etnográfica dedicada a uma etnia (seja buscando mostrá-la de modo panorâmico, seja exibindo apenas uma fração de sua complexidade sociocultural) é uma expressão equivalente da cultura (ou meio-origem) do povo enfocado (Zemb, 1980). Nesses termos, a exposição, como produto, é o meio-alvo do processo de tradução ou, o que é sinônimo, de reduzir uma realidade étnica a uma expressão culturalmente equivalente.

Essa distinção torna-se ainda mais importante quando se lida com questões relativas às disputas de bens patrimoniais. Por exemplo, se os Kayapó quisessem reivindicar a reintegração do Mekutom (parte tangível de um bem patrimonial que, no contexto da exposição, era compartilhado pelos Kayapó e pelo museu), isso, em princípio, não acarretaria maiores problemas. Entretanto, como poderiam reivindicar a posse do calendário ou do Círculo do Tempo (os quais, ainda que traduções, derivam, como artefato acadêmico e expográfico, do sistema de saberes, práticas e técnicas dos Kayapó e que, portanto,

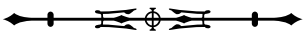


são parte intangível e intrínseca do patrimônio cultural desse povo, mas não do museu), já que esses só existiam no espaço significante da exposição?

Na relação, sempre tensa, com o outro - cuja assimetria cultural é condição mesma dessa relação -, tornou-se comum haver um comprometimento em fazer a devolutiva dos resultados de uma pesquisa para as comunidades onde as pesquisas ocorreram. No caso dos constructos acadêmicos ou museográficos, feitos a partir do material coletado em uma aldeia, podemos nos perguntar: que haveria aí a resgatar? Torna-se difícil, ou virtualmente impossível, resgatar um produto (esquema, mapa, diorama, fluxo temporal, mapa celeste) que resultou de um percurso acadêmico desde a aldeia Kayapó (meio-origem) até a exposição (meio-fim). Para que pudesse haver resgate, esses constructos teriam de ser inversamente traduzidos, qual seja, da exposição (meio-origem) para a aldeia Kayapó (meio-fim). Contudo, isso não seria, no contexto da aldeia, uma redundância?

Por outro lado, montar a exposição na aldeia (no todo ou em parte) seria mostrar, no 'lá' da aldeia, as formas de tratamento (e de transformação) mediante as quais o saber local (dos índios) foi traduzido pelos especialistas. Teríamos, assim, uma relação de equivalência, tanto cultural quanto de significação, deixando explícitas as simetrias possíveis entre os dois sistemas de saber. Outra situação possível seria se os Kayapó decidissem montar, em sua aldeia, uma exposição de seus objetos e de suas práticas culturais.

Podemos, ainda, nos perguntar acerca dos efeitos interculturais no caso de traduzir, para o sistema nativo (por exemplo, o dos Kayapó), os saberes e as técnicas da sociedade envolvente. Pensemos, por exemplo, em uma exposição que enfocasse as relações de parentesco da sociedade envolvente ou, ainda, os objetos etnográficos (sejam os instrumentos científicos) produzidos pelo sistema cultural 'daqui' (da academia). Em todo caso, haveria uma constante: a função de balcão exercida pela exposição enquanto mediação entre contextos culturais e cognitivos.

\section{CONSIDERAÇÕES FINAIS}

Uma exposição demanda leituras e interpretações. $\mathrm{Na}$ qualidade de um meio de comunicação e de mediação outro lugar onde exercitar o jogo das equivalências culturais -, uma exposição somente se completa efetivamente quando é lida, fruída e apropriada pelos visitantes. Isto não quer dizer que uma exposição se esgote nessa pluralidade de leituras, interpretações e apropriações, pois, sendo também processo e produto da signosfera, ela é igualmente marcada pela opacidade e pela incompletude.

Assim, podemos resumidamente dizer que uma exposição, como aparato de comunicação, mediação, aprendizagem e crítica, é uma prática enunciativa, elaborada com determinados objetivos, em que se produz, transmite e ordena informações sobre determinado objeto ou segmento da realidade sociocultural, e que tem relação com um campo específico do saber, da técnica ou da arte (Gonçalves, 2008). Nesses termos, uma exposição, enquanto ela mesma um gesto de interpretação, constitui-se como um discurso autorizado ou competente, e se refere a uma dada posição sociopolítica. Daí, reportar-se não somente a aspectos acadêmicos ou técnicos, mas, igualmente, a filiações histórico-ideológicas. Destarte, o conjunto desses constituintes que configuram o aparato expositivo será reinterpretado pelos visitantes que, mediante seus próprios gestos de interpretação, se apropriam, e para seus próprios fins, dos conteúdos da exposição.

Temos, assim, que uma exposição se instaura como um espaço de conhecimento e de espetáculo, em especial as exposições etnográficas que propiciam um diálogo sobre e com sociedades e culturas do outro, servindo de espelho no qual os seres humanos se veem refletidos em sua bioetno-diversidade (Bruno e Neves, 1989). Sendo um espaço de reflexão crítica, uma exposição é também espetáculo, no qual as soluções cenográficas desempenham um importante papel não apenas na apresentação estética, mas como recurso comunicacional e informacional para atrair a atenção do visitante para o que está exposto. A cenografia, enquanto linguagem visual da exposição, mobiliza uma

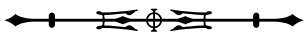


sintaxe que encadeia os elementos (objetos, etiquetas, iluminação, maquetes etc.) no espaço expositivo, e cuja semântica concerne aos diversos saberes musealizados.

Com relação ao distanciamento cultural entre objetos (mercadoria), espaço museográfico (balcão) e público (consumidor), as exposições podem ser discursivamente classificadas em duas categorias: a) exposições parafrásticas - quando os elementos da relação acima pertencem à mesma formação histórico-ideológica e, por conseguinte, em termos culturais, eles pertencem à mesma ordem (dois exemplos: a exposição do Museu Magüta $^{16}$, no espaço sociocultural da aldeia Tikuna; e a exposição do Museu de Arte Contemporânea de Niterói); b) exposições polissêmicas - quando esses elementos pertencem a ordens ou formações histórico-ideológicas distintas e, portanto, a distância cultural entre eles é irredutível (por exemplo, as exposições do Museu do Índio, na cidade do Rio de Janeiro) ${ }^{17}$.

Desse modo, no que tange à relação com o patrimônio, em uma exposição de tipo parafrástico, os bens patrimoniais - seja, por exemplo, os objetos da cultura Tikuna expostos no Museu Magüta - denotam um alto grau de ressonância (no sentido utilizado por Gonçalves, 2007b), associado a um grau elevado de aderência $^{18}$. Já em uma exposição polissêmica, conquanto seja possível detectar um grau relativo de ressonância, o nível de aderência é significativamente baixo, determinado exatamente pela distância maior entre a formação históricoideológica do objeto e a do público (considerando-se aqui, para efeito de ilustração, que objeto exposto e público não compartilham da mesma cultura).

As duas versões da exposição sobre a ciência Kayapó (a de 1987 e a de 1992), em relação ao público a que foram destinadas, são exposições polissêmicas, uma vez que a distância cultural entre o contexto de produção desse sistema de saber e o seu contexto de recepção, mesmo considerando-se a mediação/tradução fornecida pelo balcão, não pode ser reduzida aos termos da linguagem expositiva, mas a integra e, de muitas maneiras, a constitui. Tomemos, como exemplo, a seção que apresenta o mundo cosmológico dos Kayapó. Conquanto tenham-se tornado inteligíveis ao público, graças à mediação museográfica, os aspectos concernentes à lógica que sustenta a totalidade do sistema de conhecimento do mundo kayapó escapam à compreensão dos não Kayapó. $\bigcirc$ mesmo pode ser dito a respeito do calendário ecossistêmico. Para tornar apreensíveis os conceitos kayapó sobre o tempo, bem como as relações socioeconômicas entre os marcadores temporais e o ciclo de vida desse grupo étnico, foi necessário traduzi-los na forma de um modelo gráfico, empregando categorias lógicas e filosóficas próprias da sociedade envolvente e, por conseguinte, alheias à lógica e à mundivivência kayapó.

Vemos, pois, que uma exposição pode ser analisada em seus constituintes intrínsecos (projeto museográfico, projeto educativo, filiação teórica e discursiva do tema e do recorte exposto), mas também no que concerne aos lugares culturais a que pertencem os objetos, especialistas e visitantes, em que se destacam as posições relativas assumidas pelos diferentes atores que participam da cena expositiva (o 'estar aqui' e/ou o 'estar lá'); ou, ainda, no que tange ao papel de balcão desempenhado pela exposição, vista, então, como parte do processo geral da produção, circulação, troca e consumo de bens simbólicos.

Quanto à exposição "A ciência dos Mebêngôkre: alternativas contra a destruição", nossa leitura concentrouse em questões relativas às transposições e aos ajustes culturais dos dados observacionais e objetos, desde o

16 Primeiro museu organizado e mantido pelos índios Tikuna. Os Tikuna, ou Magüta, distribuem-se em áreas do Peru, Colômbia e Brasil (no estado do Amazonas). Para uma discussão mais ampla sobre museus e objetos etnográficos, ver Abreu (2008).

17 As noções de paráfrase e polissemia foram tomadas de empréstimo da teminologia própria da análise de discurso (Orlandi, 2005).

${ }^{18}$ A aderência mede o grau de afinidade, ou de mobilização, entre um sujeito (ou uma comunidade) e um traço cultural. Para mais informações sobre o uso de uma matriz ressonância + aderência, ver Borges (2011) e Borges e Oliveira (2011). 
seu contexto original de produção (o seu 'estar lá', na aldeia) até a sua inscrição museográfica (o seu 'estar aqui', no espaço expositivo, ou contexto de recepção); bem como naquelas que dizem respeito às relações que derivam do processo geral, que vai da produção de um bem simbólico (a exposição) e seu desfrute por um consumidor (visitante). Enfocamos também os papéis dos diferentes atores, a partir de uma dupla inserção, aquela que se refere às posições culturalmente relativas no espaço da ação cognitiva, descritas em termos de 'estar aqui'/'estar lá', e aquela que concerne à cadeia produtiva, em que alguns são produtores, outros são os intermediários que preparam ou levam um produto até o consumidor. Devemos ressalvar que essas posições não são fixas e que, em muitos casos, são reversíveis. Assim, por exemplo, um produtor (digamos, um Kayapó) pode também ser um intermediário e um consumidor (de uma exposição) $)^{19}$.

Com isso, pretendemos pôr em evidência alguns processos e percursos simbólicos, assim como questões referentes às distâncias de referenciais culturais (ajustes, transposições) e papéis posicionais dos atores sociais que, comumente, não são explicitados em exposições, sejam etnográficas ou não. Em suma, é justamente a função de balcão que permite a uma exposição ser, ao mesmo tempo, lugar de transposição e de ordenação de sentidos.

\section{REFERÊNCIAS}

ABREU, Regina. Patrimônios etnográficos e museus: uma visão antropológica. In: DODEBEI, Vera; ABREU, Regina (Orgs.). E o patrimônio? Rio de Janeiro: Contra Capa, 2008. p. 33-57.

ARNAUD, Expedito. A expansão dos índios Kayapó-Gorotire. A ocupação nacional (região sul do Pará). In: ARNAUD, Expedito (Ed.). O índio e a expansão nacional. Belém: CEJUP, 1989. p. 427-479.

BAUMAN, Zygmunt. O mal-estar da pós-modernidade. Rio de Janeiro: Jorge Zahar, 1998.
BELK, Russell W.; WALLENDORF, Melanie; SHERRY JR., John $F$. The sacred and the profane in consumer behavior: theodicy on the odyssey. Journal of Consumer Research, v. 16, n. 1, p. 1-36, 1989.

BENJAMIN, Walter. A obra de arte na era de sua reprodutibilidade técnica. In: BENIAMIN, Walter. Obras escolhidas. Magia e técnica, arte e política. São Paulo: Brasiliense, 1994. v. 1, p. 165-196.

BORGES, Luiz C. Museu como espaço de interpretação e de disciplinarização de sentidos. Museologia e Patrimônio, v. 4, n. 1, p. 37-62, 2011.

BORGES, Luiz C. A fala instituinte do discurso mítico guarani mbyá. 1999. Tese (Doutorado em Linguística) - Universidade Estadual de Campinas, Campinas, 1999.

BORGES, Luiz C.; OLIVEIRA, Karla Cristina Damasceno de. Pajelança musealizada. O Museu do Marajó e o imaginário marajoara. In: ENCONTRO NACIONAL DE PESQUISA EM CIÊNCIA DA INFORMAÇÃO, 12., 2011, Brasília. Anais eletrônicos... Brasília: UNB/ANCIB, 2011. p. 2818-2833.

BORGES, Luiz C.; BOTELHO, Marília Braz. Le musée et la question de la restitution - étude de deux cas concernant le patrimoine culturel brésilien. In: INTERNATIONAL COMMITTEE FOR MUSEOLOGY ANNUAL SYMPOSIUM, 33., 2010, Shangai. Proceedings... Shangai: International Committee for Museology, 2010. p. 81-91.

BORGES, Luiz C.; GONDIM, Lourdes. O saber no mito. Conhecimento e inventividade indígenas. Rio de Janeiro: Teatral, 2003.

BOURDIEU, Pierre. O poder simbólico. Rio de Janeiro: Bertrand Brasil, 2009

BOURDIEU, Pierre. A economia das trocas simbólicas. São Paulo: Perspectiva, 2003

BRUNO, Maria Cristina Oliveira; NEVES, Walter Alves. Ossos para ofício: proposta, execução e avaliação de uma exposição temporária. Ciências em Museus, v. 1, p. 39-58, 1989.

CAMPOS, Marcio D'Olne. Etnociência, etnografia e saberes locais. In: FATINATO, Maria Cecília de Castello Branco (Ed.). Etnomatemática. Novos desafios teóricos e pedagógicos. Niterói: Editora da UFF, 2009. p. 69-84.

CAMPOS, Marcio D'Olne. A cosmologia dos Caiapós. Scientific American Brasil, São Paulo, v. 14, p. 62-71, 2006.

\footnotetext{
19 Este jogo de papéis é bastante usual nas exposições realizadas pelo Museu do Índio, cujo modus operandi é fazer exposições com a participação direta da comunidade indígena, utilizando material trazido, preparado ou montado pelos índios. $\bigcirc$ mesmo acontece no National Museum of the American Indian, em Washington, cujas comunidades indígenas ali representadas são responsáveis pela curadoria das exposições.
}

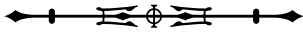


CAMPOS, Marcio D'Olne. Búzios island: knowledge and belief among a fishing and agricultural community at the coast of the state of São Paulo. In: CHAMBERLAIN, Von Del; CARLSON, John B.; YOUNG, M. Jane (Orgs.). Songs from the sky: indigenous, astronomical and cosmological traditions of the world. Bognor Regis/College Park: Ocarina Books/Center for Archaeoastronomy, 2005. p. 236-243.

CAMPOS, Marcio D'Olne. Etnociência ou etnografia de saberes, técnicas e práticas? In: AMOROZO, Maria Christina de Mello; MING, Lin Chau; SILVA, Sandra Pereira da (Orgs.). Métodos de coleta e análise de dados em Etnobiologia, Etnoecologia e disciplinas correlatas. São Paulo: UNESP/CNPq, 2002. p. 47-92.

CAMPOS, Marcio D'Olne. "Estar aqui" e "estar lá": tensões e intercessões com o trabalho de campo. In: CONGRESSO BRASILEIRO DE ETNOMATEMÁTICA, 1., 2000, São Paulo. Anais... São Paulo: USP, 2000. v. 1, p. 117-131.

CURTIS, Neil G. W. Universal museums, museum objects and repatriation: the tangled stories of things. Museum Management and Curatorship, v. 21, n. 2, p. 117-127, 2006

DOUGLAS, Mary; ISHERWOOD, Baron. O mundo dos bens: para uma antropologia do consumo. Rio de Janeiro: UFRJ, 2004.

GEERTZ, Clifford. Como pensamos hoje: a caminho de uma etnografia do Pensamento Moderno. In: GEERTZ, Clifford. O Saber local: novos ensaios em antropologia interpretativa. Petrópolis: Vozes, 1999. p. 220-245.

GEERTZ, Clifford. Estar lá, escrever aqui. Diálogo, v. 22, n. 3, p. 58-63, 1989.

GOLDSTEIN, Ilana. Reflexões sobre a arte "primitiva": o caso do Musée Branly. Horizontes Antropológicos, v. 14, n. 29, p. 279-314, 2008. Disponível em: <http://www.scielo.br/scielo. php?script $=$ sci arttext\&pid $=$ S0104-71832008000100012 $>$. Acesso em: 10 fev. 2012

GONÇALVES, José Reginaldo S. Os limites do Patrimônio. In: LIMA FILHO, Manuel Ferreira; ECKERT, Cornelia; BELTRÃO, Jane (Orgs.). Antropologia e patrimônio cultural: diálogos e desafios contemporâneos. Blumenau: Nova Letra, 2007a. p. 239-248.

GONÇALVES, José Reginaldo S. Ressonância, materialidade e subjetividade: as culturas como patrimônios. In: GONÇALVES, José Reginaldo S. (Coord.). Antropologia dos objetos: coleções, museus e patrimônios. Rio de Janeiro: IPHAN, 2007b. p. 211-234. (Coleção Museu, memória e cidadania).

GONÇALVES, Lisbeth Rebollo. Exposição e crítica - um enfoque em duas direções. In: BERTOLI, Mariza; STIGGER, Verônica (Orgs.). Arte, crítica e mundialização. São Paulo: ABCA/Imprensa Oficial, 2008. p. 45-55.

GORDON, César. Economia selvagem: ritual e mercadoria entre os índios Xikrin-Mebêngôkre. São Paulo: UNESP/ISA; Rio de Janeiro: NUTI, 2006.
HAMÚ, Denise (Ed.). A Ciência dos Mebêngôkre. Alternativas contra a destruição. Belém: Museu Paraense Emílio Goeldi, 1987. Catálogo da exposição.

INSTITUTO SOCIOAMBIENTAL (ISA). [s.d.]. Disponível em: < http:// pib.socioambiental.org/pt/povo/kayapo>. Acesso em: 17 mar. 2012.

LUKESCH, Anton. Mito e vida dos Caiapós. São Paulo: Livraria Pioneira/EDUSP, 1976.

MACHADO, Sandra Maria. Manual do professor. Exposição Ciência Kayapó, alternativas contra a destruição. Belém: Museu Paraense Emílio Goeldi, 1992a.

MACHADO, Sandra Maria. Medicina tradicional Kayapó. Exposição Ciência Kayapó, alternativas contra a destruição. Ilustração: Christiane Heringhaus. Belém: Museu Paraense Emílio Goeldi, 1992b.

MACHADO, Sandra Maria. Agricultura Kayapó. Exposição Ciência Kayapó, alternativas contra a destruição. Ilustração: Christiane Heringhaus. Belém: Museu Paraense Emílio Goeldi, 1992c.

MARX, Karl. Manuscritos econômico-filosóficos. São Paulo: Boitempo, 2004.

MARX, Karl. Para a crítica da economia política. In: MARX, Karl. Manuscritos econômico-filosóficos e outros textos escolhidos. São Paulo: Abril Cultural, 1978. p. 101-257. (Os Pensadores).

MARX, Karl. O capital. Crítica da economia política. Rio de Janeiro: Civilização Brasileira, 1971. v. 1.

OLIVEIRA, Adélia Engrácia de; HAMÚ, Denise (Orgs.). Ciência Kayapó: alternativas contra a destruição. Belém: Museu Paraense Emílio Goeldi, 1992. Catálogo da exposição.

ORLANDI, Eni Puccinelli. Análise de discurso. Princípios e procedimentos. 6. ed. Campinas: Pontes, 2005.

ORLANDI, Eni Puccinelli. Interpretação. Autoria, leitura e efeitos do trabalho simbólico. Petrópolis: Vozes, 1998.

POSEY, Darrell A. Manejo da floresta secundária, capoeiras, campos e cerrados (Kayapó). In: RIBEIRO, Berta G. (Coord.). Suma etnológica brasileira. 2. ed. Petrópolis: Vozes/FINEP, 1986. v. 1, p. 173-185.

POSEY, Darrell A.; ELISABETSKY, Elaine; ANDERSON, Anthony B.; CAMPOS, Marcio D.; OLIVEIRA, Adélia R.; DE LA PENHA, Guilherme M. A Ciência dos Mebêngôkre: alternativas contra a destruição. In: HAMÚ, Denise (Ed.). A Ciência dos Mebêngôkre: alternativas contra a destruição. Belém: Museu Paraense Emílio Goeldi, 1987. p. 12-35. Catálogo da exposição.

POVOS indígenas no Brasil. Kayapó. [s.d.]. Disponível em: < http:// pib.socioambiental.org/pt/povo/kayapo/193 > . Acesso em: 9 fev. 2012.

RODRIGUES, Aryon Dall'Igna. Línguas brasileiras. Para o conhecimento das línguas indígenas. São Paulo: Loyola, 1986. 
SANTANA, Graça; RODRIGUES, Ivelise. Peças em exposição/objects in display. In: OLIVEIRA, Adélia Engracia de; HAMÚ, Denise (Orgs.). Ciência Kayapó: alternativas contra a destruição. Belém: Museu Paraense Emílio Goeldi, 1992. Apêndice. Catálogo da Exposição.

SERRAT ANTOLÍ, Núria; FONT GUITERAS, Ester. Técnicas expositivas básicas. In: SANTACANA MESTRE, Joan; SERRAT ANTOLÍ, Núria (Coords.). Museografía didáctica. 2. ed. Barcelona: Ariel, 2011. p. 253-301.

THIEBERGER, Richard. A linguagem da tradução. In: LADMIRAL, Jean-René (Ed.). A tradução e seus problemas. Lisboa: Edições 70, 1980. p. 118-131.
TURNER, Terence. Os Mebengokre Kayapó: história e mudança social, de comunidades autônomas para a coexistência interétnica. In: CUNHA, Manuela Carneiro da (Org.). História dos índios no Brasil. 2. ed. São Paulo: Companhia das Letras/Secretaria Municipal de Cultura/FAPESP, 1998. p. 311-338.

VERSWIJVER, Gustaaf. Kayapó. 2002. Disponível em: < http://pib. socioambiental.org/pt/povo/kayapo/print>. Acesso em: 9 fev. 2012.

ZEMB, Jean-Marie. O próprio e o outro. In: LADMIRAL, Jean-René (Ed.). A tradução e seus problemas. Lisboa: Edições 70, 1980. p. 132-156. 